\title{
Alternativas de Clareamento em Dentes Desvitalizados
}

\author{
Francisco Demontieux Batista de Freitas Sobrinho ${ }^{1}$; Rodrigo Araújo Rodrigues ${ }^{2}$; \\ Fábia Ulisses Peixoto Esmeraldo ${ }^{3}$
}

\begin{abstract}
Resumo: Devido à alta demanda por um padrão de beleza criada pela sociedade, o clareamento dental é um dos procedimentos clínicos mais procurados nos consultórios odontológicos. E por isso faz-se necessário o estudo com ênfase nos tipos de condutas e materiais mais utilizados para aquele procedimento. O objetivo deste estudo é apresentar e analisar as diferentes formas de clareamento para dentes tratados endodonticamente e pigmentados, abordando os agentes clareadores mais utilizados, os diferentes métodos de procedimentos clínicos. Foi realizado através de uma revisão de literatura com a seleção de artigos de pesquisa, relato de caso e revisão de literatura escrita na língua portuguesa e inglesa. O presente artigo mostrou que é indispensável o acompanhamento clínico do dente a ser clareado, buscando o diagnóstico correto das causas propiciadoras do escurecimento dental, para que desta forma o profissional possa encontrar seguramente a técnica mais adequada para o tratamento com o intuito de fornecer ao paciente a estabilidade dos resultados decorrentes do tratamento clareador.
\end{abstract}

Palavras-chave: Dentes não-vitais. Clareamento dental endógeno. Peróxido de carbamida. Peróxido de hidrogênio. Tooth Bleaching.

\section{Whitening Alternatives in Teeth Devitalized}

\begin{abstract}
Due to the high demand for a standard of beauty that society itself creates, tooth whitening is one of the most sought after clinical procedures in dental offices. And so it is necessary to study with emphasis on the types of pipes and materials used for that procedure. The aim of this study is to present and analyse the different forms of whitening for endodontically treated teeth and pigmented, addressing the most common bleaching agents, different methods of clinical procedures. Was conducted through a review of literature with the selection of research articles, case report and review of literature written in Portuguese and English. This article has shown that it is essential the clinical follow-up of the tooth to be bleached, seeking the correct diagnosis of the causes which encourage dental blackout, so that in this way the professional can find the most suitable technique safely for the treatment in order to give the patient the stability of results arising from the bleaching treatment.
\end{abstract}

Keywords: Non-vital teeth. Endogenous teeth whitening. Carbamide Peroxide. Hydrogen peroxide. Tooth Bleaching.

\section{Introdução}

O Clareamento dental é um dos procedimentos clínicos mais procurados nos consultórios odontológicos. Este fato ocorre devido a exigência de um padrão de beleza estipulado pela sociedade, despertando assim uma maior busca por parte dos pacientes ao tratamento do clareamento dental.

\footnotetext{
${ }^{1}$ Graduado em Odontologia pela Universidade Federal de Campina Grande - PB, Brasil.

${ }^{2}$ Professor da Universidade Federal de Campina Grande - PB, Brasil.

${ }^{3}$ Odontóloga. Especialista em Ortodontia pela Universidade Potiguar - RN. E-mail: fabiaesmeraldo@ @otmail.com.
} 
A mudança da cor natural do dente ocorre na dependência de inúmeros fatores extrínsecos e intrínsecos. As manchas extrínsecas podem ser oriundas da ingestão de alimentos com corantes, pelo uso abusivo do fumo, por acúmulo da placa bacteriana e utilização de alguns tipos de medicamentos. As manchas intrínsecas possuem várias causas: alterações embriológicas do dente, doenças ocorridas na mãe durante a gestação, trauma dental, morte pulpar, acesso inadequado à câmara pulpar, má escolha de fármacos, de materiais de preenchimento, fluorose e envelhecimento dos dentes. (CARVALHO; ROBAZZA; LAGE-MARQUES, 2002).

O clareamento pode ser realizado de forma externa ou interna. O clareamento interno é um procedimento que visa restaurar a coloração dos dentes despolpados pigmentados, sendo sua conduta utilizada há muito tempo, possuindo três vantagens indiscutíveis, como: evitar o desgaste de estrutura dentária em comparação com outros procedimentos, obter resultados estéticos satisfatórios comprovados em longo prazo e onerar menos o paciente. (LOGUERCIO et al, 2002).

O clareamento de dentes despolpados é uma forma conservadora e estética na terapêutica de dentes não-vitais e escurecidos, que permite uma maior preservação da estrutura dental, a um baixo custo, especialmente quando comparada às condutas mais invasivas, como a confecção de facetas ou coroas totais (ARI; UNGOR, 2002; OLIVEIRA et al, 2006).

Muitas foram as técnicas e os materiais empregados para o clareamento dental interno. Atualmente as substâncias mais utilizadas são o peróxido de hidrogênio e o peróxido de carbamida, que têm sua ação clareadora baseada na liberação de oxigênio, levando a uma limpeza mecânica e à oxidação dos agentes pigmentantes. O sucesso do clareamento dependerá diretamente do agente clareador e da sua capacidade de penetração para alcançar as moléculas cromóforas e do possível contato com estas moléculas. (ERHARDT; SHINOHARA; PIMENTA, 2003).

O objetivo do presente trabalho é realizar uma revisão de literatura acerca dos diferentes métodos de clareamentos para dentes desvitalizados e escurecidos, expondo as técnicas utilizadas, suas indicações, vantagens, desvantagens, prognóstico e os riscos inerentes ao tratamento.

Diante do exposto nos indagamos: Quais os tipos de condutas atuais mais utilizadas no clareamento de dentes tratados endodonticamente, como do uso dos agentes clareadores mais empregados, esclarecendo suas vantagens, limitações e possíveis efeitos nocivos para um resultado clínico satisfatório, e como são tratados na literatura?

O objetivo principal do presente estudo foi fazer uma revisão de literatura, considerando as diferentes formas de clareamento para dentes tratados endodonticamente e pigmentados, abordando os agentes clareadores mais utilizados, os diferentes métodos de procedimentos clínicos. Para isso tornou-se necessário também: a) Evidenciar vantagens e limitações das técnicas atuais utilizadas para clareamento endógeno; b) Abordar diferentes técnicas utilizadas para despigmentação de dentes 
tratados endodonticamente e, c) Abordar possíveis efeitos colaterais advindo dos materiais utilizados para clareamento endógeno.

\section{Método}

Este estudo foi realizado através de uma revisão da literatura, utilizando artigos obtidos nas bases de dados: Google Acadêmico, Scielo, Lilacs, Pubmed e Capes. As palavras-chave aplicadas foram: dentes não-vitais, clareamento dental endógeno, peróxido de carbamida, peróxido de hidrogênio e tooth bleaching. O limite de data de publicação para os artigos incluídos neste estudo foram de 1988 a 2013.

Foram selecionados artigos de pesquisa, relato de caso e revisão de literatura escritos na língua portuguesa e inglesa que abordem no título, abstract ou artigo completo conceitos de clareamento dental endógeno, materiais utilizados, técnicas aplicadas, vantagens, indicações, limitações e aqueles que comparem as técnicas de clareamento endógeno.

\section{Fundamentação Teórica}

As primeiras descrições relacionadas ao clareamento foram feitas em 1864, no entanto vários compostos como cloro, hipoclorito de sódio, perborato de sódio e peróxido de hidrogênio foram utilizados, sozinhos, ou em combinações, com ou sem fonte ativadora de reação química com o objetivo de beneficiar a estética de dentes que apresentassem algum comprometimento relacionado a cor. Já em 1961, tornou-se realidade a técnica do clareamento endógeno. Esta consistia numa mistura de perborato de sódio e água, tal mistura era colocada na câmara pulpar e trocada a cada consulta odontológica. (CAMPAGNOLI; JUNIOR, 2008).

O clareamento é a busca mais conservadora de restaurar a cor normal dos dentes, através da descoloração das manchas dentais devido às reações de oxidação ou redução. Logo, o clareamento de dentes não vitais é um passo da terapia odontológica simples e de resultados conhecidos, na busca de um perfil estético capaz de alterar expressivamente a autoestima de nossos pacientes (ERHARDT; SHINOHARA; PIMENTA, 2003).

Para Campagnoli e Junior (2008) o escurecimento dental ocorre por pigmentos que envolvem a estrutura dental pelas mais variadas causas, como medicações intracanal, traumatismo, hemorragia na estrutura interna dos dentes, técnica terapêutica inadequada, materiais obturadores e seladores dos canais radiculares contendo eugenol ou cones de prata, dentre outras. Logo que esses pigmentos 
formam uma molécula capaz de refletir luz em comprimento de onda visível pelo olho humano, cuja intensidade é superior à luz refletida pela estrutura dental, sobrepondo-se então a cor do pigmento, caracterizando-se então um dente escurecido.

Segundo De Deus (1992) o tratamento endodôntico, quando seguido o protocolo correto, não constitui causa de alteração de cor dos dentes, e a maioria dos autores concordam que as variações da tonalidade são influenciadas pela presença da polpa dentária e que, quando ela deixa de existir, pode haver uma mudança na cor e no brilho do dente (HOLMSTRUP; PALM; LAMBJERGHANSEN, 1988; DAHL; PALLESEN 2003; AMATO, 2006).

Contudo, não são todos os dentes despolpados e com alteração de cor que podem ou devem ser clareados. Os critérios de indicação do tratamento clareador devem ser avaliados com muita cautela, devendo ser clareados somente os dentes que não apresentem: restaurações extensas, ou estrutura coronária insuficiente; linhas de fratura no esmalte; escurecimento por tetraciclina; raízes escurecidas e tratamento endodôntico com presença de lesões periapicais (LOGUERCIO et al., 2002).

Dentre as técnicas mais comumente aceitas para clareamento de dentes despolpados, aquela descrita por Paiva (1988), utilizando perborato de sódio e peróxido de carbamida. Esses agentes clareadores podem ser ultilizados pelas técnicas mediata, imediata ou mista. Na técnica mediata o paciente mantém o agente clareador dentro da câmara pulpar, por um periodo de três a sete dias, sendo necessária a troca até atingir a cor desejada. Na técnica imediata o agente clareador é aplicado no interior da câmara pulpar e sobre a superficie vestibular do elemento, seja ele fotoassistido ou não. Já a técnica mista, une-se à técnica mediata à imediata. É impressindivel avaliar a resposta do dente diante dos procedimentos citados, uma vez que constatada a ausência de reversibilidade de cor o profissional pode partir para outras formas de reabilitação, tais como: uso de soluções restauradoras ou peças protéticas. (REIS; LOGUERCIO, 2007).

O peróxido de hidrogênio de $30 \%$ e $35 \%$ é o material clareador mais utilizado para o clareamento de dentes desvitalizados, porém o mercado destinado a este fim disponibiliza agentes clareadores de peróxido de carbamida a 37\% em diferentes concentrações. O peróxido de hidrogênio, pode ainda ser utilizado isolado ou associado ao perborato de sódio, em uma pasta espessa, selada na câmara pulpar, com ou sem adição de calor. (SAMPAIO; FREITAS; ARAÚJO, 2010).

A principal diferença entre o peróxido de hidrogênio e o peróxido de carbamida são as reações que eles passam quando entram em contato com a estrutura dental. Ambos decompõem-se constituindo entre outras substâncias oxigênio livre, o qual é responsável pelo efeito de clareamento do dente. O peróxido de hidrogênio decompõe-se em água e oxigênio. Já o peróxido de carbamida irá se transformar inicialmente em uréia e peróxido de hidrogênio. A uréia irá dissociar-se em amônia e dióxido de carbono, e o peróxido de hidrogênio por sua vez, irá dissociar-se em água e oxigênio. A uréia produzida pela primeira dissociação do peróxido de carbamida, possui a capacidade de 
neutralizar o pH do meio: A amônia irá facilitar a penetração pois aumenta a permeabilidade da estrutura dental. (CONCEIÇÃO, 2005)

Entretanto, atualmente a prática clínica vem nos mostrando que a mudança de cor satisfatória durante o tratamento pode ser alcançada até no máximo três aplicações de agentes clareador (OLIVEIRA et al., 2003).

Um dos últimos desenvolvimentos dos agentes clareadores é a sua associação com agentes espessantes, pigmentos e catalisadores físicos e químicos, que podem ser ativados com fontes de luz halógena, arco de plasma, lasers e as atuais fontes de luz de Led, substituindo as antigas técnicas de lâmpadas quentes e espátulas aquecidas. No entanto, sabe-se que algumas fontes fotoativadoras de alta intensidade promovem o aquecimento e podem provocar efeitos diversos (ANDRADE; HUCK; FLORES, 2005).

Para a prática do clareamento, independentemente da técnica selecionada, ao acessar a câmara pulpar, é indispensável confeccionar um tampão cervical. Sendo assim, é necessário retirar cerca de 2 a $3 \mathrm{~mm}$ do material endodôntico, a partir da junção amelocementária, e criar uma barreira na entrada do canal radicular (uma camada de $1 \mathrm{a} 2 \mathrm{~mm}$ de material selador). Os materiais seladores preconizados para esse método podem ser o cimento de fosfato de zinco, o cimento de óxido de zinco e eugenol, o cimento de ionômero de vidro, material híbrido de ionômero de vidro e resina composta, ou ainda a resina composta. Essa barreira é confeccionada na tentativa de evitar a difusão dos produtos clareadores na superfície externa na junção amelocementária e prevenir uma resposta inflamatória nos tecidos periodontais circunvizinhos (LOGUERCIO et al, 2002).

Vasconcellos, Assis e Albuquerque (2000) avaliaram a competência de vedamento da região cervical de diferentes tipos de materiais usados na composição desse tampão. Foram utilizados 32 incisivos humanos extraídos, divididos em 4 grupos: Grupo I (controle): desobturação parcial do conduto deixando apenas $1 \mathrm{~mm}$ cervical desobturado; Grupo II: ionômero de vidro modificado por resina; Grupo III: cimento de fosfato de zinco; Grupo IV: cimento resinoso. Os resultados expuseram diferença significante, concluindo que nenhum dos grupos analisados apresentou selamento completo. O grupo controle ofereceu o melhor resultado, onde o material obturador usado foi colocado na região cervical, funcionando como tampão. O segundo melhor resultado foi do grupo IV (cimento resinoso), apresentando menor extravasamento que o grupo II e III. Os grupos II e III apresentaram uma infiltração estatisticamente igual entre si, e mostraram-se ineficientes no vedamento da região cervical.

Em 2004, Yui et al., com o objetivo de avaliar in vitro a influência de associações de agentes clareadores sobre o tampão cervical, utilizou a infiltração marginal por corante como fator para busca do melhor material tamponante. Foram obtidos os seguintes resultados nesses experimentos: Agentes clareadores e suas associações tiveram o mesmo grau de infiltração quando comparados ao grupo controle, não havendo diferença estatística quando se compara os materiais clareadores entre si no seu 
pontecial de extravasamento. Ainda, o tampão cervical realizado com cimento de ionômero de vidro modificado por resina (Vitremer) apresentou baixos valores de infiltração marginal em direção apical. Segundo os autores os dados deste estudo indicam que o uso do tampão cervical realizado com Vitremer sobre a guta-percha, quando utilizado no clareamento endógeno com os materiais testados, foi suficiente para diminuir a infiltração do corante em direção apical. Desta maneira, os resultados indicaram que $3 \mathrm{~mm}$ de Vitremer utilizado como barreira cervical foram eficazes no bloqueio da infiltração do material clareador em direção apical.

Em ambas as técnicas de clareamento, aconselham o condicionamento ácido com ácido fosfórico a 37\%, aplicado no interior da câmara pulpar e sobre o esmalte vestibular por 15 segundos para que ocorra uma maior desmineralização e eficiência na ação do agente clareador (BARATIERI et al, 2003).

Com os túbulos dentinários desmineralizados e relativamente desobstruídos cria-se um espaço para que o agente clareador possa agir, permitindo que os materiais restauradores liberem radicais livres que quebrem os anéis de carbono de alto peso molecular, formando radicais hidroxilas convertendo moléculas pigmentadas em moléculas menores, e consequentemente mais claras (BISPO, 2006).

No princípio, a ativação do gel clareador era realizada por meio da utilização de fontes de calor; contudo, essa prática levava à alta penetração do peróxido de hidrogênio, o que normalmente resultava em níveis altos de sensibilidade dentinária, podendo ocorrer até mesmo reabsorções internas. Hoje, busca-se reduzir a geração de calor, evitando-se, assim, o desconforto do paciente (ZANIN; JÚNIOR, 2005).

Uma das maiores preocupações referentes a clareamento em dentes despolpados, consiste na reabsorção radicular, pois há possibilidade dos agentes clareadores alcançar a dentina ou outros tecidos dentários, que reconhecem esses materiais como um corpo estranho, causando reações de defesa (DELL' ARINGA, 1999).

A reabsorção externa radicular tem sido relacionada ao clareamento em dentes endodonticamentes tratados em diferentes trabalhos.

Harrigton e Natkin (1979) descreveram sete casos de reabsorção externa em pacientes que tinham tidos seus dentes clareados através da junção da técnica imediata e da técnica mediata. Todos os dentes envolvidos tornaram-se desvitalizados após injúria traumatica no tempo que os pacientes eram jovens, sendo que não ocorreram traumas após o clareamento. Em todos os casos um agente cáustico associado com uma fonte de calor foi ultilizado. A lesões de reabsorção estavam localizadas, em todos os casos, no terço cervical da raiz.

Em dentes que sofreram algum tipo de trauma, é comum encontrar regiões pobremente reparadas sem cemento, deixando lacunas na cervical que facilitará a infiltração de peróxido de 
hidrogênio no periodonto, podendo levar a reabsorção radicular externa (HOLMSTRUP; PALM; LAMBJERGHANSEN, 1988).

Outra limitação do clareamento de dentes tratados endodônticamente é a reincidência da cor obtida de início, devendo o paciente ser informado que os resultados do clareamento não podem ser inteiramente previsíveis e que o alcance da cor desejada, assim como a sua longevidade, não pode ser garantida, em todos os casos. Entretanto esse tipo de procedimento se constitui em uma técnica muito simples, de baixo custo,de natureza conservadora e que apresenta grande eficácia e alto índice de sucesso (ATTIN et al., 2003).

\section{Discussão}

A mudança da cor que ocorre em dentes não- vitais é um dos fatores que prejudicam a harmonia do sorriso, necessitando de intervenção do Cirurgião- Dentista. (ERHARDT; SHINOHARA; PIMENTA, 2003)

Deve-se inicialmente identificar a causa da mudança de cor do dente uma vez que esta será fundamental na eleição do agente clareador, na técnica de clareamento e no prognóstico do tratamento. Descolorações oriundas de íons metálicos (pinos de prata, restaurações de amálgama) não são passíveis de um clareamento eficaz segundo os métodos modernos. Entretanto, casos de escurecimento por necrose pulpar, hemorragia intrapulpar, remanescentes pulpares após tratamento endodôntico, materiais e medicamentos endodônticos e outros podem ser clareados com resultados significativos. (LOGUERCIO et al., 2002).

É de consenso dentre os muitos autores que a técnica clareadora deve ser antecedida de um tratamento endodôntico prévio de qualidade, confeccionando um tampão cervical efetivo e da utilizando um gel clareador em alta concentração como: peróxido de hidrogênio, peróxido de carbamida associados ou não ao perborato de sódio. (SAMPAIO; FREITAS; ARAÚJO, 2010).

O peróxido de hidrogênio (H2O2) é um material clareador eficaz mas em concentrações de $30 \%$, ou mais, necessitando ser manuseado com muita precaução para impedir o aumento do risco de reabsorção radicular externa. O peróxido de carbamida é um composto orgânico contendo peróxido de hidrogênio e uréia. Em um estudo in vitro, o peróxido de carbamida provou que possuia uma propriedade clareadora igual à do peróxido de hidrogênio.O perborato de sódio existe na forma de mono-, tri-, ou tetra hidrato. Ao acréscimo de água, o H2O2 é liberado e o seu efeito clareador não é enfraquecido. (ATTIN et al., 2003).

Muitos trabalhos foram realizados confrontando os efeitos clareadores de misturas de perborato de sódio com água destilada ou o peróxido de hidrogênio em variadas concentrações (3\% à 
30\%) e não foram localizadas altercações expressivas na eficácia do clareamento (ATTIN et al, 2003). No entanto, o efeito clareador da mistura de perborato de sódio com água destilada é mais lento de forma que pode ser necessário fazer trocas mais frequentes. A permanência da tonalidade de dentes tratados com uma mistura de perborato de sódio e água é tão elevada quanto a permanência da tonalidade de dentes em que foi usada uma mistura de perborato de sódio com 3\% ou 30\% de peróxido de hidrogênio (ARI; UNGOR, 2002).

Attin et al (2003) descreveram sucesso clínico quando manusearam uma mistura de perborato de sódio e gel de peróxido de carbamida a 10\%. Esta suspensão foi empregada como preenchimento intracanal temporário após a o emprego da pasta de perborato de sódio e peróxido de hidrogênio. Os autores alegam que, a longo prazo, este procedimento contribuiu para a estabilidade da terapia de clareamento do dente.

Em se tratando da eficiencia das técnicas de clareamentos internos, alguns autores chegaram a conclusão que o sucesso do tratamento , depende da origem do escurecimento, profundidade, localização e tempo do mesmo. Podendo também estar relacionada ao produto utilizado (BARATIERI et al., 2003).

Diante das variadas técnicas clareadoras estudadas, os autores chegaram ao consenso que quando não se pode alcançar o clareamento dependendo da etiologia do escurecimento, deve-se proceder ao tratamento restaurador ou protético para atingir o resultado estético desejado (BARATIERI et al, 2003; REIS; LOGUERCIO, 2007).

Os materiais revisados para vedamentos cervicais, foram: Ionômero de vidro modificado por resina, cimento de fosfato de zinco, cimento resinoso. De acordo com os estudos, pode-se verificar que o ionômero foi o material de escolha para o selamento. (YUI et al., 2004).

Um dos fatores mais importantes, comprovado por alguns trabalhos, para determinação do risco da ocorrência de reabsorção cervical, é a alta permeabilidade da dentina coronal de dentes submetidos à tratamento endodôntico. Portanto,faz-se necessário o uso de tampão cervical adequado como forma de reduzir significativamente o risco de reabsorção cervical provocada pelos agentes clareadores (HARRIGTON; NATKIN, 1979)

\section{Conclusão}

O clareamento dental endógeno é uma técnica prática tanto para o paciente quanto para o profissional, uma vez que este possibilita um clareamento dental eficaz, com diversas possibilidades de condutas. O que o permite a escolha da mais eficaz de acordo com a causa do escurecimento, sendo também uma técnica confortável e sem maiores danos para o paciente. 
Existem diversos fatores que propiciam o escurecimento dental, alguns tratamentos ou técnicas terapeuticas desapropriadas podem ser a causa. Porém, sabe-se que o seguimento correto dos protocolos de tratamento podem evitar alterações na coloração do dente. Existem também alguns cuidados que podem ser tomados durante alguns tratamentos endodônticos que diminuem as modificações na cor do dente. Apesar disso, é possivel perceber que ocorrem algumas variações.

As substâncias comumente utilizadas para os tratamentos clareadores de dentes desvitalizados são o perborato de sódio, peróxido de carbamida e peróxido de hidrôgenio, sendo este ultimo o material clareador mais utilizado pelos profissionais da área. Tais substâncias podem ser utilizadas associadas ou separadamente em três tipos de técnicas distintas: a técnica imediata, mediata ou mista. Porém, viu-se também, que não são todos os dentes despolpados que podem passar por tratamentos clareadores, é necessário que os critérios para a indicação sejam avaliados com bastante atenção.

Em resumo, conclui-se pois, sobre a necessidade de um acompanhamento clínico do dente a ser clareado, buscando o diagnóstico correto das causas propiciadoras do escurecimento dental, para que desta forma o profissional possa encontrar seguramente a técnica mais adequada para o tratamento com o intuito de fornecer ao paciente a estabilidade dos resultados decorrentes do tratamento clareador.

\section{Referências}

AMATO, M. et al. Bleaching teeth treated endodontically: long-term evaluation of a case series. Journal of Endodontics. Baltimore, v. 32, n. 4, p. 376-378, 2006. Disponível em < http://www.ncbi.nlm.nih.gov/pubmed/16554217> Acesso em 18 fev 2014.

ANDRADE, M. F.; HUCK, C.; FLORES, V. H. O. Clareamento dental: o claremento a luz da ciência. Endodontia: Tratamentos de Canais Radiculares, Principios Técnicos e Biológicos. 2.ed. São Paulo: Artes Médicas, 2005. Cap. 31, p.1326-137.

ARI, H.; UNGOR, M. In vitro comparison of different types of sodium perborate used for intracoronal bleaching of discoloured teeth. Internacional Endodontic Journal. London, v. 35, n. 5, p. 433-436, 2002. Disponível em <http://www.ncbi.nlm.nih.gov/pubmed/12059914> Acesso em 07 ago 2013.

ATTIN, T. et al. Review of the current status of tooth whitening with the walking bleach technique . Internacional Endodontic Journal. London, v. 36, p. 313-329, 2003. Disponível em < http://www.ncbi.nlm.nih.gov/pubmed/12752645> Acesso em 05 ago 2013.

BARATIERI, Luiz Narciso et al. Odontologia restauradora: fundamentos e possibilidades. São Paulo: Santos, 2003.

BISPO, L.B. Clareamento dentário nos dias de hoje: uma revisão. Revista Dentística on line. [S. I.], v.13, n. 6, p. 2-7, 2006. 
CAMPAGNOLI, Karina Regalio; JUNIOR, Nelson Scholz. Clareamento de dentes desvitalizados: técnica LED com peróxido de hidrogênio. Ver. Clín. Odontol., vol. 4, n. 2, p. 107-112. , 2008. Disponível em <www2.pucpr.br/reol/index.php/AOR?dd1=2521\&dd99=pdf> Acesso em 22 de fev. 2014.

CARVAlhO, F. E. M. O.; ROBAZZA, C. R. C.; LAGE-MARQUES, J. L. Análise espectrofotométrica e visual do clareamento dental interno utilizando laser e calor como fonte catalisadora. Pesquisa Odontológica Brasileira. São Paulo, v. 16, n. 4, 2002. Disponível em $<$ http://www.scielo.br/scielo.php?script=sci arttext\&pid=S151774912002000400010\&lng=pt\&nrm=i so >. acesso em 4 ago. 2013.

CONCEIÇÃO, Ewerton Nocchi (Org.). Restaurações estéticas: compósitos, cerâmicas e implantes. 1. ed. Porto Alegre: Artmed. 2005.

DAHL, J.E.; PALLESEN, U. Tooth bleaching: a critical review of the biological aspects. Critical Reviews Oral Biology and Medicine. Alexandria, v.14, n. 4, p. 292-304, 2003. Disponível em < http://www.ncbi.nlm.nih.gov/pubmed/12907697> Acesso em 01 mar. 2014.

DE DEUS, Q. D. Endodontia. 5.ed. Rio de Janeiro: Medsi, 1992.

DELL'ARINGA, D. C. Alteração do ph extra-radicular com a aplicação de materiais clareadores sobre diferentes barreiras intra-radiculares. Revista Eletrônica Ecler - Endodontics Clinical Practice, Education and Research, São Paulo, v. 1, n. 2, 1999. Disponível em: $<$ http://ecler.bvs.br/scielo.php?script=sci_arttext\&pid=S1516-40551999000200003\&lng $=\mathrm{en} \& \mathrm{nrm}=\mathrm{iso} \& \mathrm{tlng}=\mathrm{pt}>$. Acesso em: 5 ago. 2013

ERHARDT, Maria Carolina; SHINOHARA, Mirela Sanae; PIMENTA, Luiz André. Clareamento dental interno. Revista Gaúcha de Odontologia. Porto Alegre, v. 51, n. 1, p. 23-29, 2003. Disponível em 〈http://www.revistargo.com.br/ojs/index.php/revista/article/viewArticle/267> Acesso em 01 mar. 2014.

HARRIGTON, Gerald W.; NATKIN, Eugene. External resorption associated with bleaching of pulpless teeth. Journal of endodontics. v. 5, n. 11, 1979. Disponível em <http://www.sciencedirect.com/science/article/pii/S0099239979800916> Acesso em 26 fev. 2014.

HOLMSTRUP, G.; PALM, A. M.; LAMBJERGHANSEN, H. Bleaching of discoloured rootfilled teeth. Endodontic Dental Traumatology. Copenhagen, v. 4, p. 197-201, 1988.

LOGUERCIO, Alessandro Dourado et al. Avaliação clínica de reabsorção radicular externa em dentes desvitalizados submetidos ao clareamento. Pesquisa Odontológica Brasileira. Copenhagen, v. 16, n. 2, p. 131-135, 2002. Disponível em 〈http://www.scielo.br/pdf/pob/v16n2/a07v16n2.pdf〉 Acesso em 28 fev. 2014.

OLIVEIRA, L. D., et al. Sealing evaluation of the cervical base in intracoronal bleaching. Dental Traumatology. v.19, p. 309-313, 2003. Disponível em <http://www.ncbi.nlm.nih.gov/pubmed/15022998> Acesso em 26 fev. 2014.

OLIVEIRA, Daniel Pinto de, et al. In vitro assessment of a gel base containing $2 \%$ chlorhexidine as a sodium perborate's vehicle for intracoronal bleaching of discolored teeth. Journal of Endodontics. Baltimore, v. 32, n.7, p. 672-674, 2006. Disponível em <http://www.orocentro.com.br/files/file-444795420.pdf $>$ Acesso em 25 fev. 2014. 
PAIVA, J. G.; ANTONIAZZI, J. H. Endodontia: bases para a prática clínica. 2. ed. São Paulo:Artes Médicas, 1988, p. 866.

REIS, A.; LOGUERCIO, A.D. Materiais dentários restauradores diretos: dos fundamentos à aplicação clínica. São Paulo: Ed. Livraria Santos, 2007.

SAMPAIO, Maíra Dias; FREITAS, Anderson Pinheiro; ARAÚJO, Roberto Paulo Correia. Análise espectrofotométrica do clareamento dental interno. Rev. Gaucha Odontol., Porto Alegre, vol. 58, n. 3, p. 363-368, 2010. Disponivel em <http://www.revistargo.com.br/viewarticle.php?id=1742> Acesso em 27 fev. 2014.

VASCONCELLOS, Walison Arthuso; ASSIS, Bruno Roque Patricio; ALBUQUERQUE, Rodrigo de Castro. Avaliação da capacidade de vedamento da região cervical por materias usados na confecção do tampão durante o clareamento dental endógeno. Publicatio UEPG Biological and Health Sciences, v. 6, n. 1, p. 29-42, 2000. Disponível em $<$ http://www.revistas2.uepg.br/index.php/biologica/article/viewFile/256/260> Acesso em 25 fev. 2014.

YUI, Karen Cristina K., et al. Influência de agentes clareadores no tampão cervical realizado com cimento de ionômero de vidro modificado por resina. Ciência Odontológica Brasileira, v. 7, n. 3, p. 60-66, 2004. Disponível em <http://ojs.fosjc.unesp.br/index.php/cob/article/view/440/365 > Acesso em 25 fev. 2014.

ZANIN, Fátima; JUNIOR, Aldo Brugnera. Clareamento dental: com luz-laser. 3 ed. São Paulo: Santos; 2005.

\section{Como Citar esse artigo (ABNT):}

FREITAS SOBRINHO, Francisco D.B.; RODRIGUES, Rodrigo A.; ESMERALDO, Fábia.U.P. Alternativas de Clareamento em Dentes Desvitalizados. Id on Line Revista de Psicologia, Julho de 2014, vol.8, n.23, p. 115125- ISSN 1981-1179. 